Published in final edited form as:

Am J Sports Med. 2014 July ; 42(7): 1567-1573. doi:10.1177/0363546514530088.

\title{
Incidence of Second ACL Injuries 2 Years After Primary ACL Reconstruction and Return to Sport
}

\author{
Mark V. Paterno, PT, PhD, SCS, ATC ${ }^{\star}, \dagger, \uparrow, \S, \|$, Mitchell J. Rauh, PT, PhD, MPH, FACSMף, \\ Laura C. Schmitt, PT, PhD ${ }^{\dagger, \ddagger}, \#$, Kevin R. Ford, PhD, FACSM ${ }^{\star *}$, and Timothy E. Hewett, PhD, \\ FACSM $^{\dagger, \ddagger, \|, \dagger †, \neq \ddagger}$ \\ Investigation performed at the Cincinnati Children's Hospital Medical Center, Cincinnati, Ohio, \\ USA
}

\begin{abstract}
Background-The incidence of second anterior cruciate ligament (ACL) injuries in the first 12 months after ACL reconstruction (ACLR) and return to sport (RTS) in a young, active population has been reported to be 15 times greater than that in a previously uninjured cohort. There are no reported estimates of whether this high relative rate of injury continues beyond the first year after RTS and ACLR.
\end{abstract}

Hypothesis-The incidence rate of a subsequent ACL injury in the 2 years after ACLR and RTS would be less than the incidence rate reported within the first 12 months after RTS but greater than the ACL injury incidence rate in an uninjured cohort of young athletes.

Study Design-Cohort study; Level of evidence, 2.

Methods-Seventy-eight patients (mean age, 17.1 \pm 3.1 years) who underwent ACLR and were ready to return to a pivoting/ cutting sport and 47 controls (mean age, $17.2 \pm 2.6$ years) who also participated in pivoting/cutting sports were prospectively enrolled. Each participant was followed for injury and athlete exposure (AE) data for a 24-month period after RTS. Twenty-three ACLR and 4 control participants suffered an ACL injury during this time. Incidence rate ratios (IRRs)

\footnotetext{
*Address correspondence to Mark V. Paterno, PT, PhD, SCS, ATC, Cincinnati Children's Hospital Medical Center, 3333 Burnet Avenue, MLC 10001, Cincinnati, OH 45229, USA (mark.paterno@ cchmc.org).

†incinnati Children's Hospital Medical Center, Cincinnati, Ohio, USA.

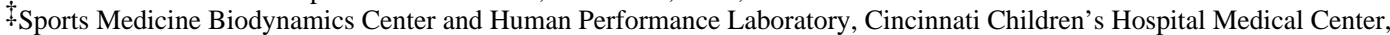
Cincinnati, Ohio, USA.

$\$$ Division of Occupational Therapy and Physical Therapy, Cincinnati Children's Hospital Medical Center, Cincinnati, Ohio, USA.

Department of Pediatrics, College of Medicine, University of Cincinnati, Cincinnati, Ohio, USA.

I Doctor of Physical Therapy Program, San Diego State University, San Diego, California, USA.

\#Division of Physical Therapy, School of Health and Rehabilitation Sciences, The Ohio State University, Columbus, Ohio, USA.

*** Department of Physical Therapy, School of Health Sciences, High Point University, High Point, North Carolina, USA.

t† Department of Orthopaedic Surgery, College of Medicine, and the Departments of Biomedical Engineering and Rehabilitation Sciences, University of Cincinnati, Cincinnati, Ohio, USA.

$\$+$ Ohio State University Sports Medicine, Sports Health \& Performance Institute, Departments of Orthopaedic Surgery, Family Medicine, Physiology and Cell Biology, College of Medicine, and the Department of Biomedical Engineering, The Ohio State University, Columbus, Ohio, USA.

Presented at the 39th annual meeting of the AOSSM, Chicago, Illinois, July 2013.

For reprints and permission queries, please visit SAGE's Web site at http://www.sagepub.com/journalsPermissions.nav
}

One or more of the authors has declared the following potential conflict of interest or source of funding: The study was supported by the National Football League Charities and the National Institutes of Health/National Institute of Arthritis and Musculoskeletal and Skin Diseases grants R01-AR049735, R01- AR05563, R01-AR056259, and F32-AR055844. 
were calculated to compare the rates (per $1000 \mathrm{AEs)}$ of ACL injury in athletes in the ACLR and control groups. For the ACLR group, similar comparisons were conducted for side of injury by sex.

Results-The overall incidence rate of a second ACL injury within 24 months after ACLR and RTS $(1.39 / 1000$ AEs) was nearly 6 times greater (IRR, 5.71; 95\% CI, 2.0-22.7; $P=.0003$ ) than that in healthy control participants $(0.24 / 1000$ AEs). The rate of injury within 24 months of RTS for female athletes in the ACLR group was almost 5 times greater (IRR, 4.51; 95\% CI, 1.5-18.2; $P=.0004)$ than that for female controls. Although only a trend was observed, female patients within the ACLR group were twice as likely (IRR, 2.43; 95\% CI, 0.8-8.6) to suffer a contralateral injury (1.13/1000 AEs) than an ipsilateral injury (0.47/1000 AEs). Overall, $29.5 \%$ of athletes suffered a second ACL injury within 24 months of RTS, with 20.5\% sustaining a contralateral injury and $9.0 \%$ incurring a retear injury of the ipsilateral graft. There was a trend toward a higher proportion of female participants $(23.7 \%)$ who suffered a contralateral injury compared with male participants $(10.5 \%)(P=.18)$. Conversely, for ipsilateral injuries, the incidence proportion between female $(8.5 \%)$ and male $(10.5 \%)$ participants was similar.

Conclusion-These data support the hypothesis that in the 24 months after ACLR and RTS, patients are at a greater risk to suffer a subsequent ACL injury compared with young athletes without a history of ACL injuries. In addition, the contralateral limb of female patients appears at greatest risk.

\section{Keywords}

incidence rate; anterior cruciate ligament reconstruction; second injury; subsequent injury

An anterior cruciate ligament (ACL) injury is a traumatic injury that occurs with high frequency during athletic participation and often results in an inability to return to pre-injury levels of activity. 2,31 Over 200,000 ACL injuries are estimated to occur in the United States annually. ${ }^{6,18,27}$ High-risk populations include athletes participating in pivoting and cutting sports, adolescent athletes, and female athletes. Prior studies have indicated that high school female athletes may suffer ACL injuries at a rate as high as 1 in 60 athletes. ${ }^{8,20}$ Anterior cruciate ligament reconstruction (ACLR) is the typical management of ACL injuries, as approximately $90 \%$ of patients who sustain an ACL injury in the United States eventually undergo ACLR. ${ }^{16}$

Despite the high percentage of ACLR after ACL injuries, outcomes may be less than optimal, including an increased risk of subsequent injuries and future knee osteoarthritis. Recent evidence indicates that subsequent ACL injuries occur with a higher frequency than previously thought; however, variability in the reported rate of second injuries remains. ${ }^{12,26,29,33}$ Wright et $\mathrm{al}^{33}$ prospectively reported that 1 in $17(6 \%)$ patients sustained a second ACL injury within 2 years after ACLR. Of these, an equal occurrence of ipsilateral retears and contralateral tears was observed. Higher rates of a second ACL injury have been reported in studies with a longer follow-up period after ACLR. In a retrospective case series study reporting 5-year outcomes after ACLR, Salmon et al ${ }^{29}$ reported that 1 in $8.3(12 \%)$ patients incurred a second ACL injury. In a 15-year follow-up study of this same cohort, Leys et $\mathrm{al}^{15}$ reported that 1 in 2.9 to 3.4 (29\%-34\%) patients suffered a second ACL injury. 
The patients in these cohorts were older (median age, 23-25 years; range, 11-62 years $)^{26,29,33}$ and generally less active compared with younger, active patients, who typically incur the greatest number of ACL injuries (mean age, $~ 16$ years). ${ }^{32}$

Methodologically, these studies reported incidence proportion estimates instead of incidence rates of patients at risk. The incidence rate is a more sensitive measure of injury risk because it adjusts for the actual extent of athletic participation, ${ }^{13}$ as sports participation after ACLR may vary because of age, confidence, fear of reinjury, residual impairments, or other factors. ${ }^{14}$ A recent study reported the incidence rate of second ACL injuries after ACLR. The authors reported an incidence rate that was 15 times greater than that of control participants, as over $25 \%$ of athletes suffered a second injury to either their ACL graft or their contralateral ACL after ACLR. Unfortunately, this study only tracked injuries and athlete exposures (AEs) for 12 months after return to sport (RTS) and therefore was unable to examine longer term outcomes related to the second injury. ${ }^{23}$

Prospective studies that examine the incidence rate in young, active patients over a longer outcome period are needed. Thus, the purpose of the current study was to determine the incidence rate of second ACL injuries in either the ipsilateral or contralateral knee, using a denominator that would account for the actual extent of AEs at risk for injury, during the first 24 months after RTS and ACLR in a young, active population. The hypothesis was that the incidence rate of a subsequent ACL injury in the 2 years after ACLR and RTS would be less than the incidence rate reported within the first 12 months after RTS but greater than the ACL injury incidence rate in an uninjured cohort of young athletes.

\section{MATERIALS AND METHODS}

\section{Participants}

These data represent a subset of a larger, prospective, longitudinal case-control study. This design was used to identify and compare the incidence of a second ACL injury (ipsilateral or contralateral) after primary ACLR and RTS to an uninjured control group. A total of 125 participants were included in this study. Of these, 78 young athletes (59 female, 19 male), who recently sustained a primary ACL injury, underwent surgical reconstruction, completed rehabilitation, and were released to return to their prior level of activity, participated in this study. All of the patients underwent single-bundle ACLR, with 39 reconstructions with ipsilateral patellar tendon grafts, 33 reconstructions with ipsilateral hamstring grafts, and 6 reconstructions with allograft tissue. Sixty-three of these patients after ACLR were included in a previous study, which reported the rate of second ACL injuries in the first 12 months after ACLR. ${ }^{23}$ Inclusionary criteria required the participants to (1) be between 10 to 25 years old, (2) have no history of a contralateral ACL injury, (3) have no history of a bilateral lower extremity or low back injury during the previous 12 months, and (4) be released by both their physician and physical therapist or athletic trainer to return to their preinjury participation level in a pivoting or cutting (level 1 or 2$)^{4}$ sport for at least 50 hours per year. All injuries represented noncontact or indirect contact primary ACL injuries. Indirect contact injuries were defined as injuries that occurred in conjunction with contact to a body part other than the involved extremity (ie, trunk). ${ }^{18}$ Contact injuries, which were operationally defined as injuries that occurred as a result of direct contact to the injured 
extremity, were excluded. The ACL injuries that occurred during the 24 months after RTS were confirmed with arthroscopic surgery or magnetic resonance imaging.

The referent group consisted of 47 healthy participants ( 34 female, 13 male), who were recruited by contacting local high school, collegiate, and athletic communities as well as internal/local advertisement. The referent group was comparable with the ACLR group with respect to activity level and primary sports participation. In addition to having no history of ACL injuries, these participants met the identical inclusionary and exclusionary criteria as the ACLR group and also participated in a minimum of 50 hours of pivoting and cutting sports per year in comparable sports. A breakdown of specific sports participation of both the ACLR and control groups is presented in Figure 1.

The study was approved by the institutional review boards of the Cincinnati Children's Hospital Medical Center and Rocky Mountain University of Health Professions, and informed consent was obtained from all participants and guardians (if applicable) before testing.

\section{Data Collection}

Demographic and anthropometric data (age, height, and weight) were collected from patients in the ACLR group at the time of RTS and from participants in the referent group at the time of initial testing.

\section{Injury Surveillance and Exposure}

Participants were enrolled into the study over an 18-month span of time. After the initial testing session at the time of RTS, participants in both groups were contacted individually by e-mail or telephone every 2 to 4 weeks for the following 24 months.

Injuries-Participants were asked to report any knee injury since their RTS, particularly ACL injuries, at each point of contact. All second ACL injuries in the ACLR group and initial injuries in the referent group, which were noncontact or indirect contact injuries, were included. ${ }^{18}$ A classification regarding mechanism (contact vs noncontact/indirect contact) was made via interview with the patient at the time of injury.

Participation Exposure-At each point of contact, participants in the ACLR and referent groups reported the number of AEs in which they participated since the previous contact date. $\mathrm{An}^{\mathrm{AE}}{ }^{17}$ was defined as participation in a game or practice session in a pivoting or cutting sport within their individual or team sport.

\section{Statistical Analysis}

Select baseline characteristics were compared between the ACLR and referent groups as well as between sexes within each group, with independent $t$ tests (a significance level $\leq$. 05). Two-year incidence rates were calculated for the ACLR and referent groups. For the ACLR group, the rate of second ACL injuries was the number of new ACL injuries per 1000 AEs at risk. Only AEs that occurred before the new ACL injury during the 24 months after their RTS were counted. For the referent group, the ACL injury rate was the number of 
initial ACL injuries per 1000 AEs at risk. Only AEs up to the initial ACL injury during the 24-month study period were counted. These rates were also calculated separately for male and female athletes. For the ACLR group, separate rates were calculated for contralateral and ipsilateral injuries.

Incidence rate ratios (IRRs) with 95\% confidence intervals (CIs) were calculated to compare the incidence of new ACL injuries in the ACLR group to the incidence of initial ACL injuries in the referent group. Similar IRRs and 95\% CIs were computed for comparison of contralateral and ipsilateral ACL injuries in the ACLR group only. For comparison with previous studies, we also determined the percentage of athletes injured without regard to the extent of participation. Differences between female and male athletes were calculated for all injury rate ratio and risk proportion comparisons. All data were analyzed using PASW (version 17.0, SPSS Inc, Chicago, Illinois, USA) and STATA (version 5.0, STATA Corp, College Station, Texas, USA) statistical packages.

\section{RESULTS}

Independent $t$ tests indicated no significant mean differences in baseline age, height, or weight between participants in the ACLR group and those in the referent group $(P>.05)$ (Table 1). No significant group differences in age, height, or weight were observed when evaluated separately for female and male participants $(P>.05)$. A similar distribution of sports participation was observed among participants in the ACLR and referent groups (Figure 1).

During the 24-month follow-up period, 23 (29.5\%) patients from the ACLR group and 4 (8.5\%) participants from the referent group sustained a noncontact or indirect contact ${ }^{18} \mathrm{ACL}$ injury. No ACL injuries due to a contact mechanism were observed during this time. Of the 23 patients after ACLR with a subsequent ACL injury (ACLR2), 16 (69.6\%) sustained contralateral ACL injuries, and 7 (30.4\%) sustained an ipsilateral graft retear; $19(82.6 \%)$ were female, and $4(17.4 \%)$ were male (Table 2). There was no difference $(P=.79)$ in the mean time from surgery to RTS between the participants in the ACLR group who sustained a second injury ( $8.3 \pm 2.0$ months) and those who did not sustain a second ACL injury (8.2 \pm 2.7 months). The mean time between RTS and the second ACL injury in the ACLR2 group was 215 days. Within a comparable period of time, there was no significant difference in the number of AEs between participants in the ACLR2 group and those who did not suffer a second ACL injury $(P=.60)$ and between participants in the ACLR2 group and those in the control group who did not suffer an initial ACL injury $(P=.33)$.

Table 2 summarizes injury rates (per 1000 AEs) for a 24-month time period. The overall incidence rate of a second ACL injury within 24 months after ACLR and RTS (1.39/1000 AEs) was nearly 6 times greater (IRR, 5.71; 95\% CI, 2.0-22.7; $P=.0003$ ) than that of healthy control participants $(0.24 / 1000 \mathrm{AEs})$ (Table 2$)$. The rate of injury within 24 months of RTS for female athletes in the ACLR group was almost 5 times greater (IRR, 4.51; 95\% CI, $1.5-18.2 ; P=.0004)$ than that for female athletes in the control group. Although only a trend was observed, within the ACLR group, female patients were twice as likely (IRR, 2.43 ; 95\% CI, 0.8-8.6) to suffer a contralateral injury (1.13/ 1000 AEs) than an ipsilateral 
injury (0.47/1000 AEs). Overall, 29.5\% of athletes suffered a second ACL injury within 24 months of RTS, with $20.5 \%$ sustaining a contralateral injury and $9.0 \%$ incurring a retear injury of the ipsilateral graft. Although not statistically significant $(P=.18)$, female participants (23.7\%) had a greater proportion of contralateral ACL injuries compared with male participants (10.5\%). Conversely, for ipsilateral injuries, the incidence proportion between female ( $8.5 \%)$ and male (10.5\%) participants was similar. The distribution of second ACL injuries by graft source is displayed in Table 3.

A Kaplan-Meier survival curve analysis (Figure 2) graphically depicted the timing of ACL injuries in the ACLR and control groups relative to exposures. Patients in the ACLR group were more likely to suffer a subsequent ACL injury earlier relative to AEs after RTS, as $30.4 \%$ (7/ 23) were injured in less than 20 AEs and 52.2\% (12/23) were injured in less than 72 AEs. Conversely, in the control group, none of the athletes were injured in the first 20 AEs, and only $1(25.0 \%)$ was injured in less than 72 AEs.

\section{DISCUSSION}

The findings of this current study support the hypothesis that the incidence rate of ACL injuries in the first 2 years after ACLR is significantly higher than the incidence rate of initial injuries in a cohort of young, healthy participants. Patients who underwent ACLR were approximately 6 times more likely to sustain an ACL injury within the first 24 months after RTS. Female athletes having undergone ACLR were almost 5 times more likely to sustain an ACL injury than female athletes with no history of an ACL injury. Almost 30\% of young athletes who returned to pivoting and cutting sports after ACLR suffered a second ACL injury in the 24 months after ACLR and RTS, with the majority of these injuries occurring in less than 72 AEs after RTS. Finally, the time from surgery to RTS was not different between those patients after ACLR who suffered a second ACL injury and those who did not sustain a second injury.

To our knowledge, this study represents the first report on subsequent ACL injury incidence rates focused on 2-year outcomes of young, active patients after RTS and ACLR. Further, to our knowledge, this study represents the first report of second ACL injury incidence rates after ACLR adjusted for actual sports participation exposure for this period. The current results indicate that young athletes who return to pivoting and cutting sports after ACLR have a 6-fold greater risk of an ACL injury than healthy participants. Because male participants in the referent group did not incur an initial injury, we were unable to formally statistically evaluate incidence rates between male participants in the ACLR and referent groups. However, the incidence rate for the entire referent cohort was in the range of previously reported rates. In a metaanalysis, the incidence rate of initial ACL injuries was reported to be between 0.011 and 0.49 per 1000 AEs for recreational, high school, and collegiate female soccer and basketball players. ${ }^{18}$ These authors also reported an ACL injury rate range of 0.007 and 0.12 per $1000 \mathrm{AEs}$ for similar male athletes. These findings are comparable with the incidence rates of our overall (0.24/1000 AEs) and female $(0.36 / 1000 \mathrm{AEs})$ referent groups but are significantly less than those of the ACLR group (1.39/1000 AEs) and female ACLR group (1.51/1000 AEs). 
Recent work from our laboratory has looked specifically at the risk of second ACL injuries in the first 12 months after ACLR and RTS. ${ }^{23}$ These data represent an extension of this initial 12-month outcome study, as all participants from the initial work were included in these 24-month outcome data. Interestingly, these data indicated that in the first 12 months after ACLR and RTS, athletes were 15 times more likely to sustain a second ACL injury when compared with a healthy control group, and female athletes were 6 times more likely to sustain a contralateral injury. When comparing the 12-month IRRs to these 24-month IRR ratio data, it appears that the greatest risk of second ACL injuries after RTS is within the first 12 months after RTS. More specifically, a large percentage of athletes appear to suffer a second ACL injury within the first 72 AEs. For a competitive, in-season athlete, this may represent a time frame as short as 12 weeks after RTS. Considering this high incidence of second injuries within relatively few AEs in the first several months after RTS and ACLR, and the work of Ardern et $\mathrm{al}^{3}$ and others, who indicated that many athletes were unable to compete at their preinjury level for greater than 12 months after ACLR, the need to reevaluate current criteria to release athletes to RTS after ACLR should be considered by the sports medicine community. Current evidence has identified modifiable predictive factors of second ACL injuries after ACLR, which include biomechanical and neuromuscular measures as well as altered postural stability. ${ }^{25}$ Future research needs to investigate if these measures could appropriately be translated into clinical RTS criteria to help reduce the risk of second ACL injuries, in lieu of temporal parameters, which appear to have no relationship to second injury rates as suggested by these data.

For comparative purposes to prior reports, we also calculated incidence proportions for both groups. The incidence proportion of a second ACL injury for those in the ACLR group within the first 24 months after RTS was $29.5 \%$ compared with $8.5 \%$ of an initial ACL injury in a cohort of young, healthy referents during the same period. The incidence proportion of a second injury after ACLR is similar to those in the studies of Pinczewski et $\mathrm{al}^{26}$ and Leys et al, ${ }^{15}$ who reported an incidence proportion of $27 \%$ at 10 - year follow-up and $29 \%$ to $34 \%$ at 15 -year follow-up, respectively, but higher than those previously reported in 2- and 5- year follow-up studies by Wright et $\mathrm{al}^{33}(6 \%)$ and Salmon et $\mathrm{al}^{29}$ $(12 \%)$, respectively. More recently, Wright et $\mathrm{al}^{34}$ reported 5 -year outcomes in a systematic review and noted second injury rates as high as $11.8 \%$ for contralateral injuries and $5.6 \%$ for ipsilateral retears. The higher incidence proportion reported in our study is likely caused by a younger, more active patient population than that previously reported by others. The greater prevalence of ACL injuries in a younger population is consistent with prior studies, which indicated that the greatest number of ACL injuries occurred between the ages of 16 and 18 years. ${ }^{32,35}$ The variability in AEs after ACLR limits the ability to compare incidence proportions between studies. In essence, there is a possibility that the difference in activity levels between younger cohorts of athletes who return to sport compared with an older, less active cohort may be the mechanism underlying the variability in second injury rates among athletes rather than age itself. In our study, the reported incidence rate, adjusted for actual sports participation at risk for injury, provides a more accurate risk estimate of future ACL injuries after ACLR. Using AEs as a more sensitive denominator to measure the injury risk, our findings indicated that the risk of a subsequent injury was highest for female athletes after ACLR, with a rate of 1.51 per 1000 AEs. In addition, this rate was particularly high 
because of the high rate of contralateral injuries in female athletes after ACLR, with a rate of 1.13 per 1000 AEs.

Within the cohort of all patients after ACLR, and the cohort of female patients, most second ACL injuries occurred in the contralateral limb. However, these differences were only nonsignificant trends (95\% CI, 0.8-8.6). The nonsignificant trends were likely caused by the small sample size and the low number of second ACL injuries among male patients in the ACLR group. An equal rate of contralateral and ipsilateral second ACL injuries was seen in the male cohort after ACLR; however, the smaller sample size of male participants may limit the generalizability of these findings of male athletes. Most notable within young female athletes after ACLR, 32\% suffered a contralateral injury within the first 24 months after RTS. The higher rate of an additional injury to a new body part relative to a reinjury is consistent with findings reported by Rauh et al, ${ }^{28}$ which noted a similar pattern in high school female athletes. The mechanism of this high rate of contralateral ACL injuries in female athletes after ACLR is likely multifactorial, inclusive of unresolved preoperative risk factors ${ }^{11}$ and residual impairments at the time of $\operatorname{RTS}^{19,30}$ and the tendency of many athletes to develop compensatory patterns, which increase stress on the uninvolved limb when returning to sport, ${ }^{5,22,24}$ especially if the uninvolved limb also had the same predisposing risk factors as the injured limb. ${ }^{25}$

Recent evidence consistently reports that a history of injuries is predictive of future injuries. ${ }^{21,28}$ Current surgical interventions for an ACL injury may adequately address the pathoanatomy; however, underlying neuromuscular and biomechanical preoperative risk factors may persist after ACLR. Rehabilitation after ACLR, if focused on postoperative impairments of the involved limb, may neglect to address modifiable risk factors in both limbs in these athletes after ACLR. Various studies have identified training programs that have successfully reduced the rate of ACL injuries in young, healthy female athletes. $1,7,9,10,17$ Future research should examine the efficacy of novel interventions throughout rehabilitation after ACLR at reducing the rate of a second ACL injury.

\section{Potential Study Limitations}

While an important strength of our study was the use of a prospective cohort study design, several limitations should be noted. A relatively small sample size of 125 participants limited our ability to examine subgroup analyses of additional variables of interest. Specifically, the smaller sample of male participants may limit the generalizability of these findings among young male athletes after ACLR. In addition, the small number and unequal distribution of participants who received various graft types limit the ability to derive any definitive conclusions regarding the likelihood of a second ACL injury related to the graft type. Finally, the cohort represented a targeted high-risk population of young athletes who planned to return to pivoting and cutting sports. This may limit the generalizability of our results to other athletic populations, particularly those who elect to return to nonpivoting types of sports. 


\section{CONCLUSION}

The results of this prospective cohort study indicate an increased rate of second ACL injuries (contralateral or graft retears) in the first 2 years after RTS and ACLR when compared with a healthy referent population in pivoting and cutting sports, especially for female athletes. In addition, these data indicate that the majority of injuries occur early after RTS, specifically less than $72 \mathrm{AEs}$, in this population. While we recommend additional research to support our findings, our data provide early evidence for the re-examination of current protocols for end-stage rehabilitation and appropriate discharge criteria before RTS after ACLR.

\section{References}

1. Alentorn-Geli E, Myer GD, Silvers HJ, et al. Prevention of non-contact anterior cruciate ligament injuries in soccer players, part 2: a review of prevention programs aimed to modify risk factors and to reduce injury rates. Knee Surg Sports Traumatol Arthrosc. 2009; 17(8):859-879. [PubMed: 19506834]

2. Ardern CL, Taylor NF, Feller JA, Webster KE. Return-to-sport outcomes at 2 to 7 years after anterior cruciate ligament reconstruction surgery. Am J Sports Med. 2012; 40(1):41-48. [PubMed: 21946441]

3. Ardern CL, Webster KE, Taylor NF, Feller JA. Return to the preinjury level of competitive sport after anterior cruciate ligament reconstruction surgery: two-thirds of patients have not returned by 12 months after surgery. Am J Sports Med. 2011; 39(3):538-543. [PubMed: 21098818]

4. Daniel DM, Stone ML, Dobson BE, Fithian DC, Rossman DJ, Kaufman KR. Fate of the ACLinjured patient: a prospective outcome study. Am J Sports Med. 1994; 22(5):632-644. [PubMed: 7810787]

5. Ernst GP, Saliba E, Diduch DR, Hurwitz SR, Ball DW. Lower extremity compensations following anterior cruciate ligament reconstruction. Phys Ther. 2000; 80(3):251-260. [PubMed: 10696152]

6. Frank CB, Jackson DW. The science of reconstruction of the anterior cruciate ligament. J Bone Joint Surg Am. 1997; 79(10):1556-1576. [PubMed: 9378743]

7. Gilchrist J, Mandelbaum BR, Melancon H, et al. A randomized controlled trial to prevent noncontact anterior cruciate ligament injury in female collegiate soccer players. Am J Sports Med. 2008; 36(8):1476-1483. [PubMed: 18658019]

8. Gomez E, DeLee JC, Farney WC. Incidence of injury in Texas girls' high school basketball. Am J Sports Med. 1996; 24(5):684-687. [PubMed: 8883693]

9. Hewett TE, Ford KR, Myer GD. Anterior cruciate ligament injuries in female athletes, part 2: a meta-analysis of neuromuscular interventions aimed at injury prevention. Am J Sports Med. 2006; 34(3):490- 498. [PubMed: 16382007]

10. Hewett TE, Lindenfeld TN, Riccobene JV, Noyes FR. The effect of neuromuscular training on the incidence of knee injury in female athletes: a prospective study. Am J Sports Med. 1999; 27(6): 699-706. [PubMed: 10569353]

11. Hewett TE, Myer GD, Ford KR, et al. Biomechanical measures of neuromuscular control and valgus loading of the knee predict anterior cruciate ligament injury risk in female athletes: a prospective study. Am J Sports Med. 2005; 33(4):492-501. [PubMed: 15722287]

12. Kaeding CC, Aros B, Pedroza A, et al. Allograft versus autograft anterior cruciate ligament reconstruction: predictors of failure from a MOON prospective longitudinal cohort. Sports Health. 2011; 3(1):73-81. [PubMed: 23015994]

13. Knowles SB, Marshall SW, Guskiewicz KM. Issues in estimating risks and rates in sports injury research. J Athl Train. 2006; 41(2):207-215. [PubMed: 16791309]

14. Kvist J. Rehabilitation following anterior cruciate ligament injury: current recommendations for sports participation. Sports Med. 2004; 34(4):269-280. [PubMed: 15049718] 
15. Leys T, Salmon L, Waller A, Linklater J, Pinczewski L. Clinical results and risk factors for reinjury 15 years after anterior cruciate ligament reconstruction: a prospective study of hamstring and patellar tendon grafts. Am J Sports Med. 2012; 40(3):595-605. [PubMed: 22184280]

16. Linko E, Harilainen A, Malmivaara A, Seitsalo S. Surgical versus conservative interventions for anterior cruciate ligament ruptures in adults. Cochrane Database Syst Rev. 2005; (2):CD001356. [PubMed: 15846618]

17. Mandelbaum BR, Silvers HJ, Watanabe DS, et al. Effectiveness of a neuromuscular and proprioceptive training program in preventing anterior cruciate ligament injuries in female athletes: 2-year follow-up. Am J Sports Med. 2005; 33(7):1003-1010. [PubMed: 15888716]

18. Marshall, SW.; Padua, D.; McGrath, M. Incidence of ACL injury. In: Hewett, TE.; Shultz, SJ.; Griffin, LY., editors. Understanding and Preventing Noncontact ACL Injuries. Champaign, Illinois: Human Kinetics; 2007. p. 5-30.

19. Mattacola CG, Perrin DH, Gansneder BM, Gieck JH, Saliba EN, McCue FC 3rd. Strength, functional outcome, and postural stability after anterior cruciate ligament reconstruction. J Athl Train. 2002; 37(3):262-268. [PubMed: 12937583]

20. Messina DF, Farney WC, DeLee JC. The incidence of injury in Texas high school basketball: a prospective study among male and female athletes. Am J Sports Med. 1999; 27(3):294-299. [PubMed: 10352762]

21. Orchard J, Seward H, McGivern J, Hood S. Intrinsic and extrinsic risk factors for anterior cruciate ligament injury in Australian footballers. Am J Sports Med. 2001; 29(2):196-200. [PubMed: 11292045]

22. Paterno MV, Ford KR, Myer GD, Heyl R, Hewett TE. Limb asymmetries in landing and jumping 2 years following anterior cruciate ligament reconstruction. Clin J Sport Med. 2007; 17(4):258-262. [PubMed: 17620778]

23. Paterno MV, Rauh MJ, Schmitt LC, Ford KR, Hewett TE. Incidence of contralateral and ipsilateral anterior cruciate ligament (ACL) injury after primary ACL reconstruction and return to sport. Clin J Sport Med. 2012; 22(2):116-121. [PubMed: 22343967]

24. Paterno MV, Schmitt LC, Ford KR, Rauh MJ, Myer GD, Hewett TE. Effects of sex on compensatory landing strategies upon return to sport after anterior cruciate ligament reconstruction. J Orthop Sports Phys Ther. 2011; 41(8):553-559. [PubMed: 21808100]

25. Paterno MV, Schmitt LC, Ford KR, et al. Biomechanical measures during landing and postural stability predict second anterior cruciate ligament injury after anterior cruciate ligament reconstruction and return to sport. Am J Sports Med. 2010; 38(10):1968-1978. [PubMed: 20702858]

26. Pinczewski LA, Lyman J, Salmon LJ, Russell VJ, Roe J, Linklater J. A 10-year comparison of anterior cruciate ligament reconstructions with hamstring tendon and patellar tendon autograft: a controlled, prospective trial. Am J Sports Med. 2007; 35(4):564-574. [PubMed: 17261567]

27. Prodromos CC, Han Y, Rogowski J, Joyce B, Shi K. A meta-analysis of the incidence of anterior cruciate ligament tears as a function of gender, sport, and a knee injury-reduction regimen. Arthroscopy. 2007; 23(12):1320-1325. e6. [PubMed: 18063176]

28. Rauh MJ, Macera CA, Ji M, Wiksten DL. Subsequent injury patterns in girls' high school sports. J Athl Train. 2007; 42(4):486-494. [PubMed: 18176621]

29. Salmon L, Russell V, Musgrove T, Pinczewski L, Refshauge K. Incidence and risk factors for graft rupture and contralateral rupture after anterior cruciate ligament reconstruction. Arthroscopy. 2005; 21(8):948-957. [PubMed: 16084292]

30. Schmitt LC, Paterno MV, Hewett TE. The impact of quadriceps femoris strength asymmetry on functional performance at return to sport following anterior cruciate ligament reconstruction. J Orthop Sports Phys Ther. 2012; 42(9):750-759. [PubMed: 22813542]

31. Shah VM, Andrews JR, Fleisig GS, McMichael CS, Lemak LJ. Return to play after anterior cruciate ligament reconstruction in National Football League athletes. Am J Sports Med. 2010; 38(11):2233-2239. [PubMed: 20610771]

32. Shea KG, Pfeiffer R, Wang JH, Curtin M, Apel PJ. Anterior cruciate ligament injury in pediatric and adolescent soccer players: an analysis of insurance data. J Pediatr Orthop. 2004; 24(6):623628. [PubMed: 15502559] 
33. Wright RW, Dunn WR, Amendola A, et al. Risk of tearing the intact anterior cruciate ligament in the contralateral knee and rupturing the anterior cruciate ligament graft during the first 2 years after anterior cruciate ligament reconstruction: a prospective MOON cohort study. Am J Sports Med. 2007; 35(7):1131-1134. [PubMed: 17452511]

34. Wright RW, Magnussen RA, Dunn WR, Spindler KP. Ipsilateral graft and contralateral ACL rupture at five years or more following ACL reconstruction: a systematic review. J Bone Joint Surg Am. 2011; 93(12):1159-1165. [PubMed: 21776554]

35. Yu B, Kirkendall DT, Taft TN, Garrett WE Jr. Lower extremity motor control-related and other risk factors for noncontact anterior cruciate ligament injuries. Instr Course Lect. 2002; 51:315324. [PubMed: 12064119] 


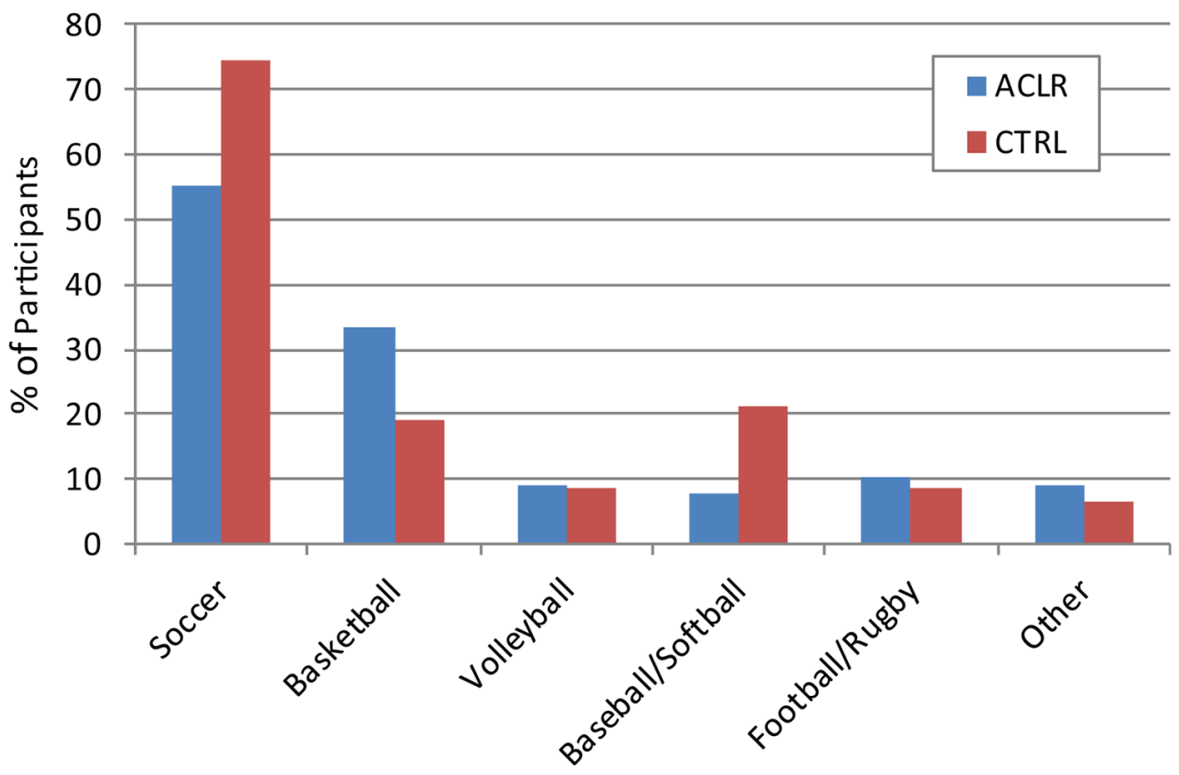

Figure 1.

Distribution of sports participation. The percentage of each cohort that participated in each individual sport. Participation in more than 1 sport was equally represented in each sport category. ACLR, anterior cruciate ligament reconstruction group; CTRL, control group. 


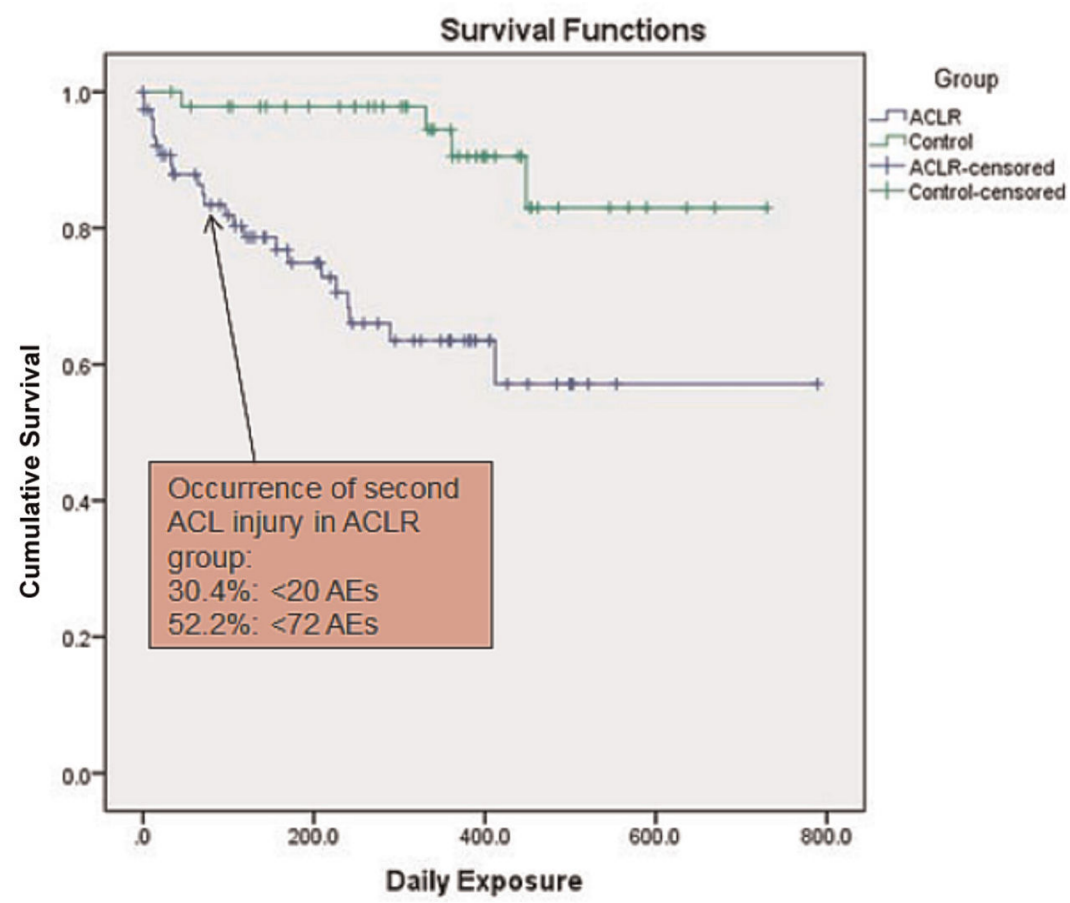

Figure 2.

Kaplan-Meier survival curve. ACL, anterior cruciate ligament; ACLR, anterior cruciate ligament reconstruction; AEs, athlete exposures in pivoting or cutting sports. 


\section{TABLE 1}

Participant Demographic Data ${ }^{a}$

\begin{tabular}{lccc}
\hline Variable & ACLR Group $(\mathbf{n}=\mathbf{7 8})$ & Control Group $(\mathbf{n}=\mathbf{4 7})$ & $\boldsymbol{P}$ Value $\boldsymbol{b}$ \\
\hline Age, y & & & \\
Total & $17.1 \pm 3.1$ & $17.2 \pm 2.6$ & .89 \\
Female & $16.9 \pm 2.8$ & $17.3 \pm 2.4$ & .42 \\
Male & $17.9 \pm 4.0$ & $16.9 \pm 2.9$ & .44 \\
Height, cm & & & \\
Total & $167.3 \pm 10.2$ & $167.4 \pm 9.0$ & .95 \\
Female & $165.0 \pm 7.2$ & $164.9 \pm 6.1$ & .98 \\
Male & $174.5 \pm 14.3$ & $173.9 \pm 12.1$ & .90 \\
Weight, kg & & & .07 \\
Total & $67.1 \pm 15.5$ & $62.2 \pm 12.3$ & .06 \\
Female & $63.6 \pm 10.3$ & $59.8 \pm 7.3$ & .23 \\
Male & $78.1 \pm 22.9$ & $68.6 \pm 19.2$ & \\
\hline
\end{tabular}

${ }^{a}$ Values are expressed as mean \pm standard deviation. ACLR, anterior cruciate ligament reconstruction.

${ }^{b}$ Independent $t$ test used for between-group comparison of means between ACLR and control groups. 


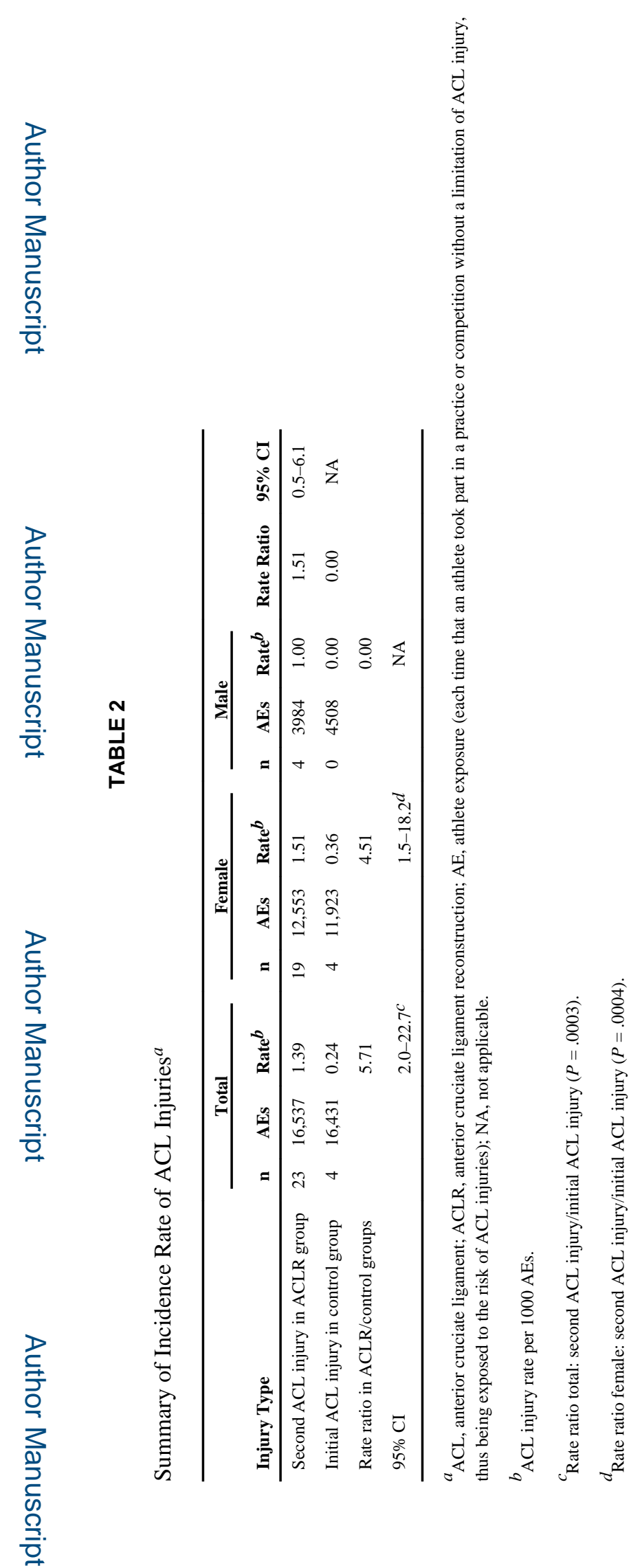

Am J Sports Med. Author manuscript; available in PMC 2015 August 01. 
TABLE 3

Distribution of Second Injuries by Graft Source

\begin{tabular}{lrrc}
\hline Graft Source & No. of Total Participants & No. of Second Injuries & Percentage Reinjured \\
\hline Allograft & 6 & 2 & 33.3 \\
Patellar bone-tendon -bone (autograft) & 39 & 11 & 28.2 \\
Hamstring (autograft) & 33 & 10 & 30.3 \\
\hline
\end{tabular}

